\title{
Atravessando o Devir Professor de Matemática
}

\author{
Crossing the Devir Math Teachers
}

Simone Moura Queiroz ${ }^{1}$

\section{Resumo}

Neste artigo buscou-se observar os movimentos transversais que perpassam o devir professor de Matemática. Com isso, criamos redes de diálogos entre o sujeito da licenciatura em Matemática, que foi agenciado pelo curso que vai moldando-o tecnicamente e reflexivamente, com algumas discussões relacionadas à Filosofia da Diferença, permitindo-nos algumas reflexões por meio dos adentramentos feitos ao plano de imanência de alguns teóricos, como Foucault, Deleuze, Guattari, Rolnik, Larrosa, dentre outros, mergulhando metaforicamente em alguns de seus conceitos (Cuidado de si, parresía, desejo, éthos, experiência, subjetivação, rizoma, devir...). O sujeito da pesquisa atravessa implicitamente este texto, deixando-nos discussões a respeito da ideia da formação, como molde proposto e expresso por meio da estrutura pedagógica do curso, por exemplo, e de encontro a esta as linhas de força, o cuidado de si, os agenciamentos, que os perpassam, que os fazem experienciar e resistirem.

Palavras-chave: Educação Matemática; Devir Professor; Cuidado de si; Parresia.

\begin{abstract}
In this article we intended to observe the transversal movements that go through the becoming a Mathematics teacher. With this, we created dialogue networks between the subject of the Mathematics undergraduate, which was influenced, through agency, by the course that molds them technically and reflexively, with some discussions related to the Philosophy of Difference, allowing us some reflections through the insights into the plane of immanence discussed by some theorists, such as Foucault, Deleuze, Guattari, Rolnik, Larrosa, and others, submerging metaphorically into some of their concepts (Care of the Self, Parrhesia, desire, éthos, experience, subjectivation, rhizoma, becoming ...). The subject of this research implicitly goes through this text, leaving us discussions about the idea of formation, as a template proposed and expressed through the pedagogical structure of the graduation course, for example, and against this, the lines of force, care of the self and agency that permeate them and make them experience and resist.
\end{abstract}

Keywords: Mathematical Education; Becoming Teacher; Care of the Self; Parrhesia.

Submetido em: 30/11/2020 - Aceito em: 30/11/2021 - Publicado em: 29/12/2021

${ }^{1}$ Doutora em Educação Matemática pela Universidade Estadual Paulista Júlio de Mesquita Filho (UNESP/Rio Claro). Professora adjunta da Universidade Federal de Pernambuco (UFPE/CAA), Brasil. Email: simonemq35@gmail.com. Orcid: https://orcid.org/0000-0002-3878-4619. 


\section{Introdução}

Existem diversas pesquisas voltadas para qual seria a melhor maneira de formar um professor, apresentando dificuldades enfrentadas para se alcançarem esses ideais. O nosso intuito, neste artigo, é observar os movimentos transversais que perpassam o devir professor de Matemática, sendo este estudo um recorte da tese de doutorado da autora (Queiroz, 2015). A academia é consequência do desejo, que os agenciou e os conduziu até a licenciatura. Não é o início. Está em meio algo. Faz parte da teia de experiências, que vai moldando o sujeito, podendo em seguida ter seu molde alterado. E assim por diante, de maneira ininterrupta.

O que se vê durante o curso de licenciatura em Matemática, desde o primeiro período até o último, são conteúdos matemáticos dos mais variados assuntos (Geometria Analítica, Cálculo, Teoria dos números, Análise Real, Estruturas Algébricas...), para o licenciando aprimorar seus conhecimentos nesta disciplina que irá lecionar. Em consonância com isso, aprendem sobre o contexto educacional como um todo, com disciplinas pedagógicas (Didática, Psicologia da Educação, Fundamentos da Educação, Políticas Educacionais, Gestão Educacional e Escolar...), assim como técnicas de ensinar (Metodologias de Ensino, Estágios Supervisionados, Didática da Matemática, Tendências em Educação Matemática, Avaliação da aprendizagem,...), acrescidas das disciplinas voltadas para a pesquisa (Metodologia da pesquisa e Trabalho de Conclusão do Curso).

Os licenciandos adentram em esferas variadas nos componentes técnicos, com os quais se depararão quando estiverem exercendo sua docência, sendo-lhes essenciais para aprimorarem o "devir professor". Todavia, o que algumas vezes não é visto em sala de aula, e que é de suma importância neste processo diante de tantas disciplinas, é criação de um espaço de discussão, de reflexão, de um diálogo franco, de um momento para a autorreflexão, visando o conhecer-se, o cuidar-se, consequentemente, à constituição do Éthos do sujeito.

Vemos programas preparando os licenciandos para se depararem com as demandas exigidas pelo mercado de trabalho, entretanto eles não estão sendo preparados para governar a si mesmos. Alguns ou muitos se perdem em meio à multidão. Dizem frases do tipo: "se todos fazem, eu também faço.", ou "se todos fazem é porque assim deve ser feito" e seguem com essa ideia. Em alguns cursos de licenciatura, infelizmente, não há momentos de reflexão sobre si, sobre voltar para si mesmo. É importante deixar explícito que muito acontece nesses espaços que consideramos técnicos, havendo atravessamentos também potentes, afinal de contas, como ressalva Deleuze (2003, p.21) mencionado por Gallo (2012, p.3), "Nunca se sabe como uma pessoa aprende..." e o que a conduz (agencia) ao aprendizado.

\section{Cuidado de si}

Foucault (2010), ao mencionar o Cuidado de si, remete a conhecer a si, que implicaria em passar mais tempo "ocupando-se com si", partindo com isso do axioma cultural grego que diz: "[...] é preciso ocupar-se consigo mesmo" (p. 383). Como cuidar implica em conhecer, logo, para conhecer, é necessário passar um tempo consigo. Em Foucault (2010) é discutido o 
DOI: $10.20396 /$ zet.v29i00.8654213

Cuidado de Si (epiméleia heautoú) de maneira genealógica, interligando-o ao Conhece-te a ti mesmo (Gnôthi Seautón), ou não. Estando nossa discussão atrelada à relação entre estes dois conceitos.

O Cuidado de si é um processo de afinar os instrumentos, como os de música. Você vai se afinando. É um eterno retorno para dentro de si. É perder-se em si mesmo, para aos poucos ir se ajeitando da forma que gostaria. É se construir, reconstruir, descontruir, é um devir. Deleuze compara o devir com o ato de escrever, ao dizer que "[...] escrever é um devir alguma coisa. Mas também não se escreve pelo simples ato de escrever. Acho que se escreve porque algo da vida passa em nós. Qualquer coisa. Escreve-se para a vida. É isso. Nós nos tornamos alguma coisa. Escrever é devir.” (Deleuze \& Parnet, 2005, p. 30).

Não há nada para além-devir, pois o devir é a exata construção do momento. A soma dos devires que vamos construindo forma em nós o povir lá na frente. Devir sempre é o movimento. Não é o tornar-se, é o estar se tornando. No movimento da vida temos muitos encontros e choques com muitas ideologias, pessoas, acontecimentos. Com um choque de uma leitura, de um encontro, de uma palavra, podemos mudar completamente nosso mundo, então aquela construção podemos abandonar e começar outra.

Devir é o movimento que compõe o momento atual e não algo que se pretende alcançar, que se almeja conseguir, obter, cujo foco está no futuro, no percorrer um caminho, cartesianamente construído, com o intuito de chegar a algum lugar. Isto diferente do devir seria o porvir, em que há uma intencionalidade movendo-o, o identificar-se, o imitar algo ou alguém.

Devir tem a ver com o conhecer-se. Hoje o que se busca muitas vezes é estar nos informando, vivendo dinamicamente, fazendo exercício na academia, indo aos médicos, trabalhando, saindo com os amigos, cuidando dos outros, de tal forma que algumas vezes não temos tempo para "perder" conosco. Com isso, nos questionamos: Como posso me cuidar se não me ocupo comigo?

Se não vivo momentos de ócio comigo, tenho que escolher posicionamentos rapidamente, tomar atitudes sobre as quais não me dei o tempo para refletir, por não "ter tido tempo". É como se vivêssemos no automático, no vaivém infindável. Vejo a notícia, opino e que venha a próxima. Outros pensam por mim, interpretam-na por mim, eu assisto aos noticiários, reproduzo o que vi e assim vou seguindo, informando-me com as meias verdades maquiadas e passadas por alguém que "teve tempo" de pensar por mim. Ao ponto de esse alguém me dizer o que realmente é melhor para mim e eu acreditar nisto, reproduzindo um desejo de manada e não o meu desejo.

Se me ocupo comigo, sei o que estou sendo. Conheço meus limites. Sabendo que determinada situação me causaria transtorno, evito me colocar nela, logo estou cuidando de mim (só posso fazer isso, se eu me conhecer). O "conhece-te a ti mesmo" é estar atento a si, é adentrar-se. O Cuidado de si envolve este conhecimento, que é único, não existe um cuidado de si genérico. São ações exercidas em si mesmos, que se assume podendo metamorfosear-se. 
De acordo com Foucault (2009) temos que

[...] ocupar-se consigo mesmo é em todo caso um imperativo que circula entre numerosas doutrinas diferentes; ele também tomou a forma de atitude, de uma maneira de se comportar, impregnou formas de viver; desenvolveu-se em procedimentos, em práticas e em receitas que eram refletidas, desenvolvidas, aperfeiçoadas e ensinadas; ele constituiu assim uma prática social, dando lugar a relações interindividuais, a trocas e comunicações e até mesmo a instituições; ele proporcionou, enfim, um certo modo de conhecimento e a elaboração de um saber (p. 50).

O cuidado de si está associado à sua relação com o outro, com o cuidar do outro (Foucault, 2010), pois não é algo isolado, os sujeitos do cuidado não vivem para si, eles ajudam outros a alcançarem o cuidado de si. Não é uma suma preparação momentânea, uma forma de vida, mas é buscar viver uma vida outra (Foucault, 2014).

Foucault (2010) menciona que esse cuidado consiste em "[...] dotar o sujeito de uma verdade que ele não conhecia e que não residia nele; trata-se de fazer dessa verdade aprendida, memorizada, progressivamente aplicada, um quase-sujeito que reina soberanamente em nós." (p. 451). ${ }^{2}$ Apresenta ainda alguns exercícios (práticas) que se baseiam "essencialmente em treinamento de resistência e abstinência, e aqueles que constituem treinamentos em pensamento e pelo pensamento" (idem). Ensinamentos por ele garimpados dos gregos. Trata-se de ser objeto de estudo de si mesmo.

A ideia das "tecnologias do eu"3 (Foucault, 2008) leva o sujeito a examinar a si mesmo, não de uma maneira isolada, mas no contexto social, mediante as suas múltiplas afetações, o afetar e ser afetado pelo meio/sujeito. Trata-se de técnicas específicas utilizadas para entender a si mesmo. "Cuando se pregunta cuál es el principio moral más importante en la filosofía antigua, la respuesta imediata no es «Cuidarse de sí mismo»” (p. 50). É com base nos gregos que Foucault $(1994,2009,2011,2013,2014)$ inicia seu discurso relacionado ao Cuidado de si, todavia menciona que "Hemos heredado la tradición de moralidad cristiana que convierte la renuncia de sí en principio de salvación. Conocerse a sí mismo era paradójicamente la manera de renunciar a sí mismo.” (p. 54). Estudou na história os distintos costumes dos homens acerca de si mesmo.

Enfim, o que temos é que o Cuidado de si implica numa experiência de si, podendo ocorrer apenas ao ocupar-se consigo, tendo com isso que se conhecer, experimentar-se, sem tornar-se um eremita, pois o Cuidado com o outro está intrínseco no Cuidado de si.

\footnotetext{
${ }^{2}$ Neste trecho do estudo de Foucault (2009) ele aborda a Cultura de si e "por essa expressão é preciso entender que o princípio do cuidado de si adquiriu um alcance bastante geral” (p. 50).

${ }^{3}$ Tecnologia de si consiste em: técnicas que permiten a los individuos efectuar un certo número de operaciones en sus propios cuerpos, en sus almas, en sus pensamientos, en sus conductas, y ello de un modo tal que los transforme a sí mismos, que los modifique, con el fin de alcanzar un cierto estado de perfección, o de felicidad, o de pureza, o de poder sobrenatural, etc., etc. Permítaseme que llame a ese tipo de técnicas, las técnicas o tecnologías de uno mismo [the self] (Foucault, 2008, p. 35-36, rodapé)
} 
É a conquista da autonomia, onde o sujeito em seu plano de imanência reconhece as linhas de força, de subjetivação, que o tem como mira, mas também conhece a vontade de potência e de poder que o formam, portanto, agarra aquelas que o move, que deseja, e afasta as que o tira da trilha dos seus desejos, atualizando suas virtualidades imanentes. O sujeito é produto e produtor de si mesmo. (Cavamura, 2013, p. 1)

O que se pretende com o Cuidado de si apresentado é constituir um Éthos nos licenciandos de Matemática, contribuindo em seu devir professor.

\section{Parresía}

Contudo, é inerente a esse Cuidado de si, implica em governar a si mesmo, conhecer a verdade sobre si, a sua verdade e, com isso, ter a coragem não apenas de falar e assumir a sua verdade, mas de praticá-la, tendo a mesma prática com o outro, através da fala franca. A isto se denominou Parresía, sendo quem a pratica um parresiasta.

Portanto, a parrhesía (a libertas, o franco-falar) é esta forma essencial [...] é uma palavra que, do lado de quem a pronuncia, vale como comprometimento, vale como elo, constitui um certo pacto entre o sujeito da enunciação e o sujeito da conduta. $\mathrm{O}$ sujeito que fala se compromete. No mesmo momento em que diz "eu digo a verdade", compromete-se a fazer o que diz e a ser sujeito de uma conduta, uma conduta que obedece ponto por ponto à verdade por ele formulada. [...] Não pode haver ensinamento da verdade sem que aquele que diz a verdade dê o exemplo desta verdade, e é por isto também [...] (Foucault, 2011, p. 365).

Com isso, temos que, a princípio, “[...] eu penso essa verdade e que, pensando-a, eu a digo, é isso que é indispensável ao ato parresiástico.” (Foucault, 2013, p. 62). Todavia, não fica apenas na enunciação, pois "o sujeito se liga ao enunciado, à enunciação e às consequências desse enunciado e dessa enunciação" (idem, p. 65). O que temos é que "a parresía é uma maneira de se vincular livremente a si mesmo no enunciado da verdade [...] é a livre coragem pela qual você se vincula a si mesmo no ato de dizer a verdade." (idem, p. 64).

O parresiasta, ao fazer um pacto consigo, se arrisca a dizer a verdade, sendo não apenas aquele que enuncia, pois ele vive de acordo com a verdade enunciada, mas também aquele que correndo o risco de perder a vida. Teoria e prática, dizer e fazer se entrelaçam, constituindo uma mesma força. O parresiasta é aquele que "se levanta, toma a palavra, diz a verdade diante do tirano e arrisca a vida." (idem, p. 59) Ele não teme o dizer-a-verdade a quem quer que seja, inclusive o tirano, mesmo sabendo que, ao pronunciar a verdade, esta pode lhe custar a existência. Eles "aceitam morrer por ter dito a verdade" (idem, p. 56).

Que verdade tão idolatrada, que pode levar à morte, seria essa? É aquela que “[...] nós a pensamos, nós a estimamos, nós a consideramos efetivamente, nós mesmos autenticamente, como autenticamente verdadeira.” (idem, p. 62) Ela é gerada em nós mesmos e por nós assumida. Para se chegar a essa verdade, encontramos o Cuidado de si como premissa. Poderíamos arriscar dizendo que aqui teríamos um silogismo hipotético condicional do tipo 
"Se eu exercito o Cuidado de si, então posso alcançar parresía." Um parresiasta só o é porque governa a si (cuida de si) mesmo.

O sujeito precisa exercitar o Cuidado de si, para alcançar a parresía. Contudo, para exercitar o Cuidado de si, tem que falar a verdade para si mesmo. É uma dupla afetação. Uma retroalimentação. Quanto mais ele pratica a parresía, mais cuida de si. Quanto mais cuida de si, mais pratica a parresía. É um movimento que nos leva de um ao outro.

A prática parresiasta, a coragem da verdade, a fala franca, é estabelecida unicamente com o outro, que é essencial, não existindo uma prática parresiasta para si.

A parresia é, portanto, o dizer tudo, mas não tudo o que vier à boca, mas tudo relativo à verdade. Dizer coisas verdadeiras em busca do progresso do outro [...] em busca de sua ascensão à autonomia e ao seu governo pessoal. É ajudar a retirar o sujeito da condição de governado pelos outros para a condição de governado por si mesmo. (Cavamura, 2013, p. 3-4).

É importante nos mantermos vigilantes, para observarmos a veridicção de nossos discursos, para que as verdades ditas não fiquem dependendo do interlocutor, mas totalmente do emissor. Não podemos ficar mudando o que consideramos verdadeiro diante de cada pessoa e/ou situação. Isso não quer dizer que, em alguns momentos, não venhamos a ser afetados por nosso interlocutor, repensando nossos discursos. São devires. Afinal de contas, é o afetar e ser afetado que nos constituem como sujeitos. O que se considera verdadeiro também pode ser provisório, pois os discursos são produzidos e mobilizados em relações de poder-saber. Somos sujeitos múltiplos, todavia múltiplas verdades ou verdades convenientes ao interlocutor não são interessantes. O parresiasta não muda para agradar o outro, pois ele está comprometido eticamente com sua forma de veridicção, com o que considera verdadeiro. Entretanto, é preciso compreender que uma atitude parresiástica não é fácil e que a relação parresiástica pura, segundo Foucault, não existe ou é algo raro na contemporaneidade.

A formação do Éthos é algo que não se restringe aos profissionais da educação, mas a todos. O ideal seria preparar o sujeito desde criança, nas escolas e fora delas. O que diferencia o licenciando de Matemática é que, além da parresía técnica, do discurso técnico da Matemática, ele precisa conhecer, compreender e buscar praticar em sua docência a parresía socrática, do Cuidado de si. Esses discursos não são excludentes, apesar de terem domínios diferentes.

\section{O sujeito da licenciatura em Matemática}

Aos poucos durante a licenciatura os estudantes vão se deparando com alunos da Educação Básica, que não aprendem como eles, os quais podem não ter tido dificuldades com a Matemática no ensino básico, mas têm agora ao assumirem a postura de professor. Isso os fez repensar conceitos relacionados ao ato de ensinar, inventados a partir de suas experiências. É um novo aprendizado. Aprendizado este que não tiveram na formação acadêmica, pois é algo que se vive fora da universidade. Não faz parte da formalidade acadêmica, do molde, todavia está implicitamente atrelado a ela, pois a academia transpassa o 
sujeito. São aprendizados - o da academia e o que está fora dela - que ocorrem concomitantemente e que, em diversos momentos, convergem, alterando-se mutuamente.

Consideramos aprendizado o ato de aprender. Para isso, citamos Deleuze (2009). Ele frisa que "aprender vem a ser tão-somente o intermediário entre não-saber e saber, a passagem viva de um ao outro. Pode-se dizer que aprender, afinal de contas, é uma tarefa infinita” (p. 160), pois, à medida que se aprende, modifica-se, transforma-se...

O sujeito assimila, reage, constitui suas formas de consciência e tende a se transformar. É por isso que o sujeito, que está sendo inserido nesse contexto, não conta apenas com suas atividades e experiências, senão também com a de seus semelhantes (do presente e do passado) transitando assim do estado de ignorância para o de conhecimento. Dessa forma uma ação individual é realmente coletiva, pois depende desse acúmulo e sempre está em função das condições sociais em que esteja localizada. Sendo o ato de Aprender algo além de uma simples ligação entre objetos [objeto da aprendizagem] e sujeitos, é uma constante e criativa transformação pela interação entre sujeitos e objetos. (Queiroz \& Posada-Balvin, 2014, p.7)

"Somos seres condicionados, mas não determinados." (Freire, 2003, p. 17), pois, “de que valeria a obstinação do saber se ela apenas garantisse a aquisição de conhecimentos, e não, de uma certa maneira e tanto quanto possível o extravio daquele que conhece? [...] perceber de forma diferente da que se vê é indispensável para continuar a ver ou refletir" (Foucault, 2012, p.191). Isto implica que vamos transformando-nos à medida que aprendemos, assim como modificamos nossa maneira de ver o objeto que estamos estudando. Um altera o outro. Alteram-se. Constituem-se.

Em Veiga-Neto (2002, p. 32), temos que “[...] o que se pensa é instituído pelo discurso que, longe de informar uma verdade sobre a realidade [...] o máximo que pode fazer é colocá-la como uma re-presença, ou seja, representá-la." A realidade é a mesma, o objeto de aprendizagem é o mesmo, o que modifica é a maneira de se interpretar e/ou representar o objeto de aprendizagem. Por exemplo, quando somos alunos, observamos a Matemática de uma maneira como aquele que tem o objetivo de aprender, entretanto assumindo a postura de professor, passamos a ver o mesmo objeto (a Matemática) com um olhar distinto, pois nosso objetivo passa a ser o de ensinar, não que com isso não aprendamos.

Além disso, esse devir docente está inserido em uma sociedade específica, estando os sujeitos, professores e aprendizes dessa universidade, em um contexto próprio de transformações constantes e diversas, influenciadas por anseios e exigências sociais, políticas, econômicas, morais, que cobram desses sujeitos posicionamentos, atribuindo-lhes responsabilidades específicas do contexto em que se encontram. Os movimentos transversais que perpassam a formação de professores têm origem na aridez "do fora", no Poder/Saber, no Biós, nas memórias e nas experiências. Portanto, observar esses professores-em-invenção, isoladamente dessa realidade em que estão inseridos, restringe nosso olhar. Por isto que, ao observarmos a sala de aula, nossa pretensão é de a vermos como 
DOI: 10.20396/zet.v29i00.8654213

Um local onde além de possuir relação de poder-resistência (das forças), há uma correlação existencial entre essa relação com o campo do saber (pelos discursos proferidos: linhas de visibilidade e enunciação), estando saber e poder entrelaçados, sendo essa relação poder-saber-poder contínua, em que uma possibilita a outra. Além desses aspectos, que compõem o dispositivo, encontramos na subjetivação (voluntária/perceptível ou involuntária/imperceptível [...] (Queiroz \& Posada-Balvin, 2014, p.9)

Entender que a sala de aula constitui-se em um território de discursos nos permite visualizá-lo como um território de resistências ao poder. Linhas de visibilidade e de enunciação. Essas linhas permitem que entendamos a rede de poder/resistência instaurada nesta microssociedade. Isto constitui os corpos desejantes que compõem a sala de aula.

Os licenciandos trazem suas experiências para sala de aula. Assim como cegos, ao fazerem um molde, que, mesmo sendo instruídos por professores videntes, dependem inteiramente das mãos para conseguirem construir um objeto semelhante àquele moldado em sua mente, apresentado pelo professor. Mesmo não vendo como ficou, mesmo não sendo igual, é uma aproximação.

Você tem que moldar, mas não vai sair exatamente do jeito que você queria [...] Um dos aspectos mais interessantes da cerâmica é que quem trabalha com ela enfrenta, cotidianamente, pequenos problemas, obstáculos e incidentes, e precisa aprender a lidar com eles. (Kastrup, 2008, p. 189)

Nesse aspecto é que a formação de professores se encontra. Criam-se moldes, constituídos a partir de diversos desejos, sendo estes expressamente formalizados no Projeto Pedagógico do Curso (PPC). Todavia, são muitas variáveis e percalços com que tanto o licenciando quanto o professor das disciplinas da graduação vão se deparando. Com isso, aqueles moldes, criados a partir da estrutura filosófica do curso e misturados com crenças e concepções dos professores, mesclam-se em sua mente, com o que, para o licenciando, seria o "professor ideal", constituído por anos de experiência como discente e/ou docente. Isso pode fazê-lo distanciar-se desse modelo mental, desse molde em que trabalhou por anos e que o agenciou para o curso de licenciatura em Matemática.

Ao vivenciar as novas experiências na academia e fora dela, o licenciando pode dar-se conta de que elas não se encaixam nos modelos que lhe foram apresentados. Percebe que não adianta imitá-los. Reproduzi-los. Com isso, ele se depara com outra maneira de se ver como professor, dissonante do molde acadêmico, aquele que tem início e fim, pois trata-se de um devir. "Devir é jamais imitar, nem fazer como, nem ajustar-se a um modelo, seja ele de justiça ou de verdade. Não há um termo de onde se parte, nem um ao qual se chega ou se deve chegar." (Deleuze \& Parnet, 1998, p. 3).

A formação de professores não se inicia com o diploma de licenciado, de acordo com a ótica que estamos explorando neste texto, nem ao cursar as disciplinas nas licenciaturas, 
nem quando já começa a lecionar ${ }^{4}$. Ela se inicia muito antes. Com isso advêm questionamentos sobre a gênese dessa formação. Afinal de contas, quando o professor começa a se formar? Acompanhada de outro tipo, pois se é uma formação, em algum momento chega-se ao final dela. Então quando termina?

Relacionado a essas perguntas e outras similares, temos que "O que conta em um caminho, o que conta em uma linha é sempre o meio e não o início nem o fim." (Deleuze \& Parnet, 1998, p. 24) Não há como determinar o momento que iniciou o desejo pela docência, assim como o fim é algo que se encontra no horizonte e não tem como visualizar, isso porque "O homem é, sem dúvida, um animal que se auto interpreta." (Larrosa, 2011, p. 41). Rever a si mesmo, aos outros, às situações, aperfeiçoa-se, reedifica-se. Reitera-se.

Chega-se ao momento em que "Futuro e passado não têm muito sentido; o que conta é o devir-presente: a geografia e não a história, o meio e não o começo nem o fim, a grama que está no meio e que brota pelo meio, e não as árvores que têm um cume e raízes." (Deleuze \& Parnet, 1998, p. 20). Essa grama é aquilo que brota, o entre-meio, o que cresce no entorno do que foi instituído. Seria como uma linha de fuga. Mas, fugir de quê, resistir a quê? Seria fugir de uma formação arborizada, dos discursos plantados, das verdades absolutas, dos mitos reproduzidos, enfim dessa ideia de formação produzida "em série". Sabendo que "[...] pensar, nas coisas, entre as coisas é justamente criar rizomas e não raízes, traçar a linha e não fazer o balanço. Criar população no deserto e não espécies e gêneros em uma floresta. Povoar sem jamais especificar.” (Deleuze \& Parnet, 1998, p. 22, grifo do autor).

É imprescindível entender como funcionam as linhas de força, a relação de poder/saber, dos dispositivos ${ }^{5}$ em que habita, assim como conhecer a si mesmo. Pois, para se resistir, é preciso saber o que o atinge, quais as suas marcas, que desejos o impulsionam, em suma, é preciso conhecer-se. É preciso olhar para si mesmo, distinguindo as linhas de forças (linhas de poder) e, a partir deste reconhecimento, optar por se deixar afetar ou não por elas, de acordo com seus desejos. Tem-se a possibilidade de vergá-las.

A relação de poder faz parte da vida do profissional da educação, sendo o estado de dominação algo abominável, contrário ao proposto pelo Cuidado de si (Foucault, 2009). Com isso, temos que não basta “[...] p professor saber mais Matemática e conhecer mais recursos ou métodos didáticos se o encontramos imerso e paralisado por uma rede de poder e saber que veda sua 'liberdade pedagógica'." (Silva \& Souza, 2012, p. 3-4), pois o Cuidado de si, é algo importante no desenvolvimento do trabalho pedagógico. Lembrando que...

\footnotetext{
${ }^{4}$ Sabe-se que o diploma é visto como o fim da formação inicial e o que vem em seguida é corriqueiramente denominado como formação continuada, destoando da ideia de devir docente, em que não existe esta barreira, este início e fim, em vez disto há continuidade.

${ }^{5}$ Dispositivo é o lugar, mas pode ser também o não-lugar, onde ocorre as relações de saber e poder e os processos de subjetivações. Para compreender melhor o dispositivo na visão de Foucault, Agamben e Deleuze ler o capítulo 5 de Silva et al. (2018).
} 
Não é possível cuidar de si sem se conhecer. O cuidado de si é certamente o conhecimento de si - este é o lado socrático-platônico -, mas é também o conhecimento de um certo número de regras de conduta ou de princípios que são simultaneamente verdades e prescrições. Cuidar de si é se munir dessas verdades: nesse caso a ética se liga ao jogo da verdade. (Foucault, 2012, p. 269)

O Cuidar de si, o ter a coragem da verdade fazem parte do devir professor, quando lhes propiciam tornarem-se profissionais que "[...] traçam linhas próprias, fazem escolhas, seguem seus desejos, compõem seu material pedagógico e exercem sua autonomia como docente." (Bovo, 2011, p. 170). Isso os faz criarem "[...] modos de vida outros; transformar a vida assujeitada em uma vida livre, autônoma [...]" (Bovo, 2011, p. 166). Essa vida livre é o que Foucault (2012) chama de "[...] prática da liberdade, a prática refletida da liberdade [...]" (p. 267), lembrando que, "[...] para praticar adequadamente a liberdade, era necessário se ocupar de si mesmo, cuidar de si, ao mesmo tempo para se conhecer." (p. 268).

Quando se refere à Autonomia, parte fundamental do Cuidado de si, Bovo pensa nesta "[...] como uma possibilidade de enfrentar os problemas da Educação na atualidade. Trata-se de um modo de vida: um exercício diário e constante do Cuidado de si." (p. 175), lembrando: “A autonomia não é cedida a ele, mas é uma força que vem de dentro dele!" (p. 178) É tendo autonomia que se pode resistir, desde sua "formação" acadêmica, produzindo:

[...] linhas de fuga, não para fugir, mas para lutar. [...] De fato, é preciso estar no curso de licenciatura, fazer parte de tal processo para resistir às subjetivações impostas pela própria licenciatura... Resistir às subjetivações... Resistir aos hábitos — o maior fluxo de forças conservadoras atuantes na licenciatura - da própria formação de professores de Matemática. (Tartaro, Cavamura \& Souza, 2014, p. 7).

Essa "[...] linha de fuga é uma desterritorialização." (Deleuze \& Parnet, 1998, p. 30), seria como desabitar esse território existencial de dominação, para resistir a ele, em outro território.

Acreditamos que é com esse perfil de resistência que o professor deve ir se constituindo. Com isso reafirmamos o dito por Tartaro, Cavamura e Souza (2015), no artigo deles: "[...] o que propomos é a invenção do ser professor. Pensar a formação de professores de Matemática é ter coragem de abrir-se para o novo constantemente e não para certezas, pois estas não podem existir.” $(2015$, p.7)

É algo que vai além da formação profissional, das técnicas de ensino e conhecimentos Matemáticos. O que se "propõe" é uma formação transpassada pelo Cuidado de si. Uma formação que tem em vista o sujeito constituindo-se como professor, ciente de que o devir se inicia bem antes de ele adentrar o curso superior e prossegue para além de sua graduação.

\section{Licenciatura em Matemática - mais algumas reflexões}

Ignorar como termina para nós significa que o percurso, o meio, é algo mais valioso que o fim, pois "[...] o que constitui o interesse principal da vida e do trabalho é que eles lhe permitem tornar-se diferente do que você era no início.” (Foucault, 2012, p. 287). Nisto podemos sentir a manifestação do desejo como algo que nos impulsiona, que nos conduz. 
Em relação ao licenciando temos que a postura inicial relacionado ao "ser" docente de este ao adentrar o curso de licenciatura poderá ir alterando, à medida que eles observam outra maneira de ensinar, assim como das teorias lidas e de algumas práticas vivenciadas. É o novo moldando-se, formando-se, aberto a mudanças, às experimentações, caminhando fora de sua zona de conforto.

Nesse devir vão se moldando, ou seria melhor dizer, deixando-se guiar pelas teorias que trazem consigo como deve ser "o" professor, deparando-se com a realidade, compondo novas explicações teóricas, novas formas de pensar, formando-se docente, para em seguida reformar-se - ou seria descontruir velhos preconceitos e dar passagem à construção de um professor outro -, seguindo este movimento continuamente.

Para esses licenciandos, a experiência com a docência, neste momento, não é apenas uma experiência como um leitor - refletir o fazer - de livros, artigos ou outros materiais acadêmicos, nem a de um observador - ver o fazer. É liberar-se dessas formas corriqueira para poder avançar até o - saber fazer. É trabalhar-se como um protagonista que experimenta/leciona Matemática - a prática, o refletir, o ver, o fazer, o inventar-se professor de Matemática -, assumindo-se como professor, enquanto dentro de si, travam-se as primeiras batalhas entre teorias e práticas.

A prática do professor é um revezamento entre uma teoria e outra e ao mesmo tempo um revezamento entre uma prática e outra. Nesta pesquisa a prática do professor de Matemática não é entendida apenas como as ações do professor em sala de aula, também compreende seu pensamento, suas ideias, suas opiniões, seus discursos. (Bovo, 2011, p. 4)

Mesmo ainda não tendo a prática de anos de ensino, esses licenciandos trazem consigo algumas experiências, não com o ato de lecionar, propriamente dito. A vivência de um projeto que integra Universidade e Escola Básica permite considerarmos que a experiência como docente de Matemática, possibilitada no projeto, como "[...] o que me passa e o que, ao passar-me, me forma ou me transforma, me constitui, me faz como sou, marca minha maneira de ser, configura minha pessoa e minha personalidade [...]" (Larrosa, 2002, p. 28). Por isso, a experiência exige um parar para pensar/refletir, pois é algo que nos afeta, nos marca, nos modifica, nos transpassa sendo a continuidade uma de suas características, pois pode se originar de outras experiências - até então "adormecidas" -, assim como levar a outras experiências - ao transcender o tempo vivenciado, o contínuo presente-passado-futuro.

No momento em que esses licenciandos estão lecionando, observam que experiências outras, não ligadas diretamente ao contexto de sala de aula, vivenciadas em outros dispositivos, não ficam fora da sala de aula, mas, sim, fazem parte de um eterno retorno ao movimento de inventar-se professor de Matemática. São inseparáveis do sujeito e, à medida em que atua como professor, novas experiências são acrescidas às antigas, havendo uma cisão, fusão, fissão, ruptura, entrelaçar, enfim um movimento do devir professor de Matemática. Os fluxos de força que percorrem uma sala de aula, as marcas dos sujeitos alunos e professores -, o mero contato entre sujeitos já os afetam mutuamente. Fluxos de 
forças, marcas e afetações. Deleuze comenta como era seu relacionamento com a sala de aula:

É preciso achar a matéria da qual tratamos, a matéria que abraçamos, fascinante. [...] Muitas coisas acontecem numa aula... Uma aula é algo que se estende de uma semana a outra. É um espaço e uma temporalidade muito especiais. ... Mas há um desenvolvimento interior numa aula. $\mathrm{E}$ as pessoas mudam entre uma semana e outra. O público de uma aula é algo fascinante. (Deleuze \& Parnet, 2005, p. 80)

O nosso fascínio pelo que lecionamos pode ser agenciador. As pessoas mudam, como mencionado, pois somos sujeitos da experiência e, apesar de múltiplos, é o sujeito que perpassa pelos mais variados dispositivos, sendo afetado e afetando-os.

É preciso estar totalmente impregnado do assunto e amar o assunto do qual falamos. Isso não acontece sozinho. É preciso ensaiar, preparar. É preciso ensaiar na própria cabeça, encontrar o ponto em que... É muito divertido, é preciso encontrar... É como uma porta que não conseguimos atravessar em qualquer posição. (Deleuze \& Parnet, 2005, p 81).

O pedagógico está atualmente sendo adquirido no curso de licenciatura, que os "ensina a ensinar", levando-os a perceber que, durante a experiência como professor, se recriam e, paralelo a isto, eles vão aprendendo a conhecer mais da disciplina que irão lecionar. Sendo-nos interessante "transvalorar" este diálogo existente na academia sobre a formação Matemática do professor de Matemática com a "prática". Quando escrevemos "transvalorar", não se trata nem de negar, muito menos reproduzir, mas de carregar essa formação com experiências (Larrosa, 2002). "Nada aprendemos com aquele que nos diz: faça como eu. Nossos únicos mestres são aqueles que nos dizem "faça comigo" e que, em vez de nos propor gestos a serem reproduzidos, sabem emitir signos a serem desenvolvidos no heterogêneo." (Deleuze, 2009, p. 31).

Abriremos uns parênteses para discutirmos a respeito da disciplina em questão, a qual estes licenciandos estão preparando-se para lecionar que é a Matemática, temos no Parâmetro Curricular Nacional:

A constatação da sua importância apóia-se no fato de que a Matemática desempenha papel decisivo, pois permite resolver problemas da vida cotidiana, tem muitas aplicações no mundo do trabalho e funciona como instrumento essencial para a construção de conhecimentos em outras áreas curriculares. Do mesmo modo, interfere fortemente na formação de capacidades intelectuais, na estruturação do pensamento e na agilização do raciocínio dedutivo do aluno. (Brasil, 1997, p. 15).

Esse trecho é um discurso de justificativa, defendendo a importância de se trabalhar a disciplina de Matemática em sala de aula, pois, além de se fazer presente no cotidiano dos alunos, ela desenvolve potencialmente a capacidade mental deles. Sendo algo tão interessante e necessário, por que temos tanta aversão a ela? Algo está desarmonioso.

Outro trecho remete-se aos “[...] princípios decorrentes de estudos, pesquisas, práticas e debates" (Brasil, 1997, p. 19) referentes ao ensino da Matemática, apresentados pelos PCN. Dos nove, selecionamos este: "A atividade Matemática escolar não é “"[...] olhar para coisas 
prontas e definitivas", mas a construção e a apropriação de um conhecimento pelo aluno, que se servirá dele para compreender e transformar sua realidade.” (idem, p. 19).

Não estamos discordando desse princípio apresentado, pois se trata de um ideal, do desejo de um grupo de pesquisadores relacionado ao ensino de Matemática. Pesquisadores que há anos estudam a relação e o desempenho dos alunos com a Matemática, além da postura dos professores diante desta disciplina. Mesmo fora da sala de aula, observam as demandas sociais, traçando, a partir desse aglomerado de informações "coletadas", um caminho a ser percorrido. Caminho este que destoa do discurso parresiasta, pois, mesmo que seja a verdade de um grupo de pesquisadores, essa é apenas uma verdade destes pesquisadores. Eles não vivem da verdade que discursam. Eles não estão em sala de aula. Apenas a observam. Coletam informações e não as experienciam, não as vivem. São falas prescritivas, impostas e não parresiastas.

Voltando ao trecho destacado, nos questionamos: como nossos licenciandos irão fugir do "olhar para coisas prontas e definitivas" se foi assim que aprenderam?

Fechando os parênteses e continuando a discussão... Temos que nós, licenciados em Matemática, não fomos formados, mas sim licenciados para falarmos em nome da Matemática. Muitos de nós não fomos educados matematicamente, pois, durante a graduação, aprendemos técnicas de ensino, ou seja, maneiras de como ensinar Matemática. Então, “[...] como se pode saber se alguém é competente em geral na ordem da tékhne e, especificamente, na ordem dessa 'tékhne'?” (Foucault, 2014, p. 118)

Foucault (2014) nos aponta dois critérios: um relacionado aos mestres; outro, às obras do discípulo, “[...] se esses mestres eram bons mestres, se eram capazes de formar bons alunos." (p. 118). Fazendo um deslocamento do mencionado para a Educação ${ }^{6}$ temos que não bastava apenas serem bons, terem o conhecimento técnico, teriam que saber formar outrem. $\mathrm{O}$ aluno, por meio do diálogo franco com seu professor, tem suas verdades postos à prova, sendo este último a "pedra de toque" do aluno. O aluno tem que saber quando ele não sabe, para que não permaneça na mediocridade. Fortalecer a vida na verdade, fugindo da mentira. A verdade é causadora de microrrevoluções e algumas vezes as maiores revoluções são aquelas contra as mentiras que há em nós. Muitas dessas mentiras se tornam refúgios de alguns professores por anos na docência, que preferem não as admitir. Cabe ao professor criar um ambiente em que deve imperar o Éthos da verdade. Com isso, o professor precisa assumir suas verdades relacionadas não apenas ao Cuidado de si, mas também à técnica, à Matemática. Enfim, a enunciação só atinge o interlocutor se estiver de acordo com sua prática.

"E o segundo critério, poderíamos dizer, é o da obra [...] (podemos até admitir que, sem mestre, ele foi capaz de fazer algo válido)" (p. 119). Com isso temos que "[...] é preciso

\footnotetext{
${ }^{6}$ A Educação não foi o foco dos estudos de Foucault, apesar de suas discussões perpassá-las, pois, ao envolver a hermenêutica dos sujeitos, podendo inserir nesta o sujeito da educação. Ou seja, utilizamos os discursos apresentados por Foucault em nossas análises e produção de saberes em outro campo, o da Educação.
} 
cuidar dos jovens, ensinar os jovens a cuidar de si mesmos." (Foucault, 2014, p. 111). Diante do ensinamento, é que o jovem segue adiante. Contudo, não tem como ensinar alguém que não esteja interessado em aprender, que não tenha desejo de aprender. Além disso, o que temos hoje é um discurso da tékhne vazia, já que mesmo o licenciando cursando Matemática nunca viu como se faz Matemática.

Temos um curso de graduação em que os professores dão aula de currículo (matérias propostas nos mais variados planos nacionais), pois há um currículo a cumprir e recebemos título.

O aluno tem o currículo formado e pronto. Existem professores de graduação hoje no Brasil que não faz pesquisa. Somos licenciados em Matemática, para darmos aulas de Matemática, sem nunca termos feito Matemática, ou seja, não conhecemos o discurso matemático e temos que dar aula de Matemática. Não conhecemos como se produz o saber matemático e damos aula de Matemática. A opção de trabalhar com grupo de pesquisa e colocar os alunos em contato com a Matemática poderia ser uma saída. Sendo possível conhecer os conceitos que perpassam os diversos assuntos da Matemática, podendo relacioná-lo, ter-se-ia subsídio para discutir o currículo da licenciatura, com a parresía técnica e não mantendo o foco apenas no currículo. Mas, seria isto fundamental para se ensinar Matemática? A falta deste conhecimento afetaria o ensino de Matemática? Será que a prática da docência na educação básica necessitaria de o professor ter experienciado a prática do matemático? São reflexões que nos perpassam quando adentramos às discussões voltadas para a licenciatura em Matemática.

Seria interessante analisar os discursos que perpassaram a formação dos saberes, para investigar como ocorreu, não apenas historicamente, mas de uma maneira cartográfica, observando as linhas de força que os transpassaram e subjetivaram, os discursos da época, assim como as linhas de fuga, os agenciamentos ocorridos, as rupturas. Para isso tem que haver interesse por parte do professor, desejo que o mova. Afinal de contas, se nem o professor que ministra a aula deseja conhecer isso, como fará seus alunos desejarem?

Aderir à doutrina do ensino da Matemática, que consiste em uma explicação rápida do conteúdo, para se entender o teorema, apresentando as fórmulas com exemplos, passando em seguida listas de exercícios é algo mais linear. Acabou o ensino. Para isto existem muitas técnicas e tendências que contribuem para este formato de ensino e que em momento algum relacionam os conteúdos. Isso impossibilita os alunos de compreenderem "o todo", as múltiplas relações entre os mais variados conteúdos, vendo-os apenas em blocos isolados e desconectados.

Assim os licenciandos reproduzem o que aprenderam a fazer com relação à Matemática, exercitando a memorização (é importante, mas não é o suficiente), em vez da parresía técnica, pois não sabem como fazê-lo. Suas obras são condizentes com a de seus mestres. 
DOI: $10.20396 /$ zet.v29i00.8654213

A verdade desse discurso, passada pelo mestre e reproduzido pelo aluno, deveria estar ligada à parresía técnica, que consiste em dizer a verdade desse "mundo técnico". O mestre teria que ter a autonomia de falar por si, em vez de reproduzir discursos técnicos. Mas, se o próprio mestre não tem acesso a esse discurso, como pode o aluno ser um parresiasta de ordem técnica?

\section{Mais algumas considerações}

Vimos que mesmo o Cuidado de si e a tékhne sendo de domínios diferentes, o professor de Matemática, em seu discurso técnico, também pode de alguma forma ajudar na formação do sujeito ético. Poderia ser essa a meta da licenciatura em Matemática: Contribuir com movimentos que auxiliem o movimento do devir professor de Matemática de seus licenciandos, bem como a constituição de seu Éthos.

"Forma-se" não é apenas conhecer os conceitos matemáticos, nem aprender técnicas de como melhor ensinar, mas aprender a ver o outro a partir de si. "Dentro de um curso de formação de professores devem estar presentes, além dos téchnes matemáticos e pedagógicos, caminhos que proporcionem o conhecimento de si mesmo, uma formação que proporcione um movimento de se conhecer, de se cuidar. Tornar-se." (Tartaro, Cavamura \& Souza, 2014, p. 6).

Não basta o professor apenas dominar o conteúdo, ele precisa estar atento ao que ocorre à sua volta - tanto nos âmbitos global, com as tecnologias, quanto local, com $a$ comunidade em que se encontram -, assim como ao sujeito da aprendizagem: o aluno. Sendo este último o foco de sua profissão, deve recorrer a metodologias mais apropriadas para facilitar a aprendizagem deles, respeitando o tempo de cada um em aprender. Devido a isto, é necessário estar sempre se atualizando e, por mais difícil que seja, devido às amarras que o sistema educativo lhe impõe, procurar ministrar aulas dinâmicas e contextualizadas, apresentando a Matemática ao aluno, adaptando-a à linguagem do aluno, em vez de o aluno à da Matemática, tendo este que existir diante desse universo de leis, regras, pressupostos e símbolos desconhecidos, com uma linguagem própria e em nada semelhante à sua. Estrias que (des)potencializam.

Para isto o texto nos traz que "Não se pode governar os outros, não se pode bem governar os outros [...] se não se está ocupado consigo mesmo" (Foucault, 2010, p. 35). Sendo assim, antes de ser "professor para os outros", é preciso ser "professor de si mesmo".

Como ser professor de si mesmo? O cuidando de si seria o caminho para se chegar a isto, sendo necessário, como já mencionado, ter o conhecimento de si, "dobrar-se sobre si" (Foucault, 2010, p. 63), em outras palavras, "pertencer 'a si', ser 'seu' [...] somente de si mesmo é que se depende" (Foucault, 2009, p. 70). Para isso é preciso ter uma experiência consigo, que, de acordo com Larrosa (2011), é “[...] o resultado de um complexo processo histórico de fabricação no qual se entrecruzam os discursos que definem a verdade do sujeito, as práticas que regulam seu comportamento e as formas de subjetividade nas quais se constitui sua própria interioridade.” (p. 42-43) 
Essa "[...] experiência de si que constitui o sujeito" (Larrosa, 2011, p. 55) conduz ao conhecimento de si, podendo a partir daí exercer a soberania sobre si, governar e dominar seus desejos, buscando ser temperante, controlando suas paixões, pois é "[...] sabendo se conduzir bem que ele saberá conduzir, como convém, aos outros”. (Foucault, 2009, p. 95).

Isso porque o "[...] cuidar de si é um imperativo proposto àqueles que querem governar os outros" (Foucault, 2009, p. 69). É um dever, pois é na “[...] relação consigo, a modalidade e o tipo de relação consigo, a maneira como ele mesmo será efetivamente elaborado enquanto objeto de seus cuidados" (Foucault, 2010, p. 108), que ele agirá com os outros. "É preciso 'ter cuidado consigo'; é esse o princípio do Cuidado de si que fundamenta a sua necessidade, comanda o seu desenvolvimento e organiza a sua prática. Mas é necessário [...] ocupar-se consigo mesmo..." (Foucault, 2009, p. 49).

Com já mencionado este ocupar-se consigo “[...] não constitui um exercício de solidão, mas sim uma verdadeira prática social.” (Foucault, 2009, p. 57). Não é obrigar os outros a fazerem da forma que se supõe ser a melhor, pelo contrário é agir de acordo com suas verdades e limitações (identificadas através das "práticas de si"), sem impô-las, mas respeitando as verdades e limitações dos outros.

O Cuidado de si está presente neste tipo de atitude, que deve "[...] abster-se e romper com a atitude geral [...] não isolar-se; o melhor é 'sem se confundir com a multidão, fazer as mesmas coisas, porém de outra maneira"” (Foucault, 2009, p. 65). Isso condiz com o se reconhecer profissional, o cuidar-se como professor, buscando por mudanças, conhecendo sua realidade.

\section{Referências}

Bovo, A. A. (2011). Abrindo a caixa preta da escola: uma discussão acerca da cultura escolar e da prática pedagógica do professor de Matemática. Tese de doutorado em Educação Matemática. Rio Claro: Universidade Estadual Paulista.

Brasil. (1997). Secretaria de Educação Fundamental. Parâmetros curriculares nacionais PCN - Brasília: MEC.

Cavamura, N. R. B. (2013). Michel Foucault e a Coragem da Verdade: uma reflexão sobre o professor parresiasta. Anais do Encontro Nacional de Estudantes de Pós-Graduação em Educação Matemática, Vitória, Brasil, ES, 17.

Deleuze, G. (2009). Diferença e Repetição. São Paulo: GRAAL.

Deleuze, G., \& Guattari, F. (1997). Mil Platôs: Capitalismo e esquizofrenia, 4. São Paulo: 34.

Deleuze, G., \& Parnet, C. (1998). Diálogos. São Paulo: Escuta.

Deleuze, G., \& Parnet, C. (2005). O abecedário de Gilles Deleuze. Disponível em <http://stoa.usp.br/prodsubjeduc/files/262/1015/Abecedario+G.+Deleuze.pdf>. Último acesso em 16/05/2020.

Foucault, M. (1994). Ditos e escritos, 6. Paris: Gallimard.

Foucault, M. (2008). Tecnologías del yo. Buenos Aires: Paidós. 
DOI: $10.20396 /$ zet.v29i00.8654213

Foucault, M. (2009). História da Sexualidade 3: o cuidado de si (9a ed.). São Paulo: Graal.

Foucault, M. (2010). A hermenêutica do sujeito (3a ed.). São Paulo: Editora WMF Martins Fontes.

Foucault, M. (2011). Vigiar e Punir: História da violência nas prisões (39a ed.). Petrópolis: Vozes.

Foucault, M. (2012). Ditos e escritos V: ética, sexualidade e política (3a ed.). Rio de Janeiro: Forense Universitária.

Foucault, M. (2013). Governo de si e dos outros: Curso dado no Collège de France (19821983). São Paulo: Martins Fontes.

Foucault, M. (2014). A coragem da verdade: Curso dado no Collège de France (1984). São Paulo: Martins Fontes.

Freire, P. (2003). Pedagogia da autonomia: saberes necessários à prática educativa. São Paulo: Paz e Terra.

Gallo. S. (2012). As múltiplas dimensões do aprender... Anais do Congresso de educação básica: aprendizagem e currículo, Florianópolis, SC, Brasil, 2.

Kastrup, V. (2008). O Lado de Dentro da Experiência: atenção a si mesmo e produção de subjetividade numa oficina de cerâmica para pessoas com deficiência visual adquirida. Psicologia: ciência e profissão, 28 (1), 186-199.

Larrosa, J. (2002, janeiro) Notas sobre a experiência e o saber da experiência. Revista Brasileira de Educação, s/v (19), 20-28.

Larrosa, J. (2011). Tecnologias do eu e educação. In: T. T. SILVA. (Org.), O sujeito da educação (pp. 35-86). Petrópolis: Vozes.

Queiroz, S. M., \& Posada-Balvin, F. A. (2014). Movimentos que perpassam uma sala de aula de Matemática do ensino básico. Anais do Encontro de Matemática do Agreste Pernambucano, Caruaru, PE, Brasil, 1.

Queiroz, S. M. (2015). Movimentos que permeiam o devir professor de Matemática de alguns licenciandos. Tese de doutorado em Educação Matemática. Rio Claro: Universidade Estadual Paulista.

Silva, M. T D., \& Souza, A. C. C. (2012). As Práticas de Si no Contexto da Educação Matemática. Anais do Encontro Brasileiro de Estudantes de Pós-graduação em Educação Matemática. Canoas, RS, 16.

Silva, M. M. L., Costa, L. R. da S., Soares, R. M., \& Queiroz, S. M. (2018). Cuidado de si e experiência: Movimentos que perpassam a Educação Matemática na Pós-Modernidade. Anais Encontro de Matemática do Agreste Pernambucano. Caruaru, PE, Brasil, 5.

Tartaro, T. F., Cavamura, N. R. B., \& Souza, A. C. C. (2014). Por que a Universidade não forma um professor de Matemática? Anais do Congresso Nacional de Formação de Professores e Congresso Estadual Paulista sobre Formação de Educadores. São Paulo, SP, Brasil, 2 e 12.

Veiga-Neto, A. (2002). Olhares... In: M. V. Costa (Org.), Caminhos investigativos: novos olhares na pesquisa em educação (pp. 23-38) (2a ed.). Rio de Janeiro: DP\&A. 